\title{
LATERAL AND UPLIFT STATIC LOAD TESTS OF PRECAST CONCRETE PILE
}

\author{
Jialin Zhou ${ }^{1}$, Erwin $\mathrm{Oh}^{1}$, Xin Zhang², Hongsheng Jiang², Peisen Wang ${ }^{3}$, Wei $\mathrm{Liu}^{2}$ and Shuangli Wei \\ ${ }^{1}$ School of Engineering, Griffith University, Australia \\ ${ }^{2}$ School of Civil Engineering, Shandong Jianzhou University, China \\ ${ }^{3}$ School of Civil Engineering, Tianjin University, China
}

*Corresponding Author, Received: 8 March 2017, Revised: 25 March 2017, Accepted: 20 April 2017

\begin{abstract}
In order to perform environmental construction, eliminating the dust contamination caused by welding reinforcement cages and blending concrete onsite, as well as diminishing the noise pollution caused by striking precast piles, three non-displacement precast piles subjected to lateral loading and another three that were subjected to vertical uplift loading were tested. The lengths of these tested piles were $24.7 \mathrm{~m}, 26.6 \mathrm{~m}$ and $28 \mathrm{~m}$ with the same cross-section. The soil was removed before these piles were placed in the required location. The horizontal and vertical movements of these piles under cycling loading and progressive loading were investigated through static load tests. Furthermore, six pairs of vibration wire strain gauges were welded in one pile which was applied with uplift loading for load transfer observation and shaft resistance analysis. Results suggest that the critical and ultimate loads of lateral loaded piles and ultimate loads of uplift loaded piles increase with the pile length, and in the pile with the welded gauges, that the axial force decreases with depth along the pile, increasing with applied loads provided by hydraulic jacks. In addition, the distribution of unit shaft resistances is determined and the propagations of friction resistances are analyzed.
\end{abstract}

Keywords: Non-displacement, Precast concrete pile, Static load tests (SLTs), Load transfer

\section{INTRODUCTION}

The utilization of bored piles or driven piles is accepted worldwide in deep excavation engineering. Different to a Soil Mixing Wall (SMW) in which the inside $\mathrm{H}$-steel pile can be pulled out after the underground construction is finished, the driven pile or cast-in-situ pile can be used as part of the building. The use of these passive piles as a retaining structure can improve the slope stability and hence decrease the amount of soil excavation required. These piles protect the buildings including underground structures near the construction site, and to some extent, they can also resist water permeation.

Compared to driven piles which need to be transferred from the manufacturing factory, castin-situ piles are used more commonly in excavation construction as these bored piles are cast once the holes are drilled and soils are removed, which improves the construction process. However, the disadvantage of this time-saving construction is that the welding of the reinforcement cage and blending the concrete at the construction site can cause severe environmental issues. Since 1995, the discharge of carbon dioxide in China has been 5.5 times higher than in America and 13.8 times higher than in Japan [1]. It has been reported in the Chinese news that the ejection of industrial dust increased to 11.75 million tons in 2011 [2] and that construction waste accounted for $30 \%-40 \%$ of total municipal solid waste in 2011 [3]. This environmental problem can be controlled when substituting bored piles with driven piles. However, because of the close proximity between passive piles in excavation construction and their immense size, driving these piles can squeeze the soils, consequently leading to a soil compaction effect. The best way to handle this issue is to excavate the soil first and then lower the driven pile into the drilled hole; it is worth noting that this method also diminishes noise pollution. The diameter of this hole cannot be larger than the diameter of the pile because once there is a gap between the concrete surface of the pile and soil, there will be no friction resistance which will result in decreased pile capacity.

The construction method that removes an amount of soil first and later lowers the driven pile raises questions concerning the mechanism of friction resistance of the pile. There is much research related to static load tests for determining the bearing capacity of the pile. By comparing base grouted bored piles with traditional slurry stabilized bored piles under static load tests with welded wire vibration strain gauges, a significant increase in skin friction resistance has been observed [4]. Most researchers have considered vertical compressive static load tests and interpretation of the test results for pile capacity determination; others have investigated the load 
transfer characteristic of piles. However, studies of the load transfer mechanism of this nondisplacement driven pile under vertical uplift loads are very limited.

With technological developments, the statnamic method and dynamic methods, which contain CASE and CAPWAP methods, are also used for capacity determination under vertical loading and are replacing the conventional static load test progressively. For the determination of ultimate lateral bearing capacity of a nondisplacement driven pile, which is used as a retaining structure, a lateral static load test still needs to be conducted. Different to the vertical static load test, lateral load tests are conducted for five cyclic loads, and after recording the horizontal movements, the next loading is then applied.

In order to determine the lateral critical load of these non-displacement piles, three lateral static load tests were conducted at Jinan City, in China. As mentioned previously, in order to avoid a soil compaction effect, soil is removed first in the construction site; however there is very limited research on the use of these piles with consideration of load transfer and friction distribution analysis. For this study, another three uplift loaded pile tests were conducted, and for the specific uplift loaded pile, vibrating wire strain gauges were applied for load transfer determination. The further study should be observing the deflection behavior along the pile length as when this passive pile used in deep excavation, this passive pile is subjected to changed earth pressure caused by soil excavation and concrete, steel supports and/or anchor application. In this paper, the construction process of these non-displacement precast piles is also provided; it is expected that this paper can provide practical information for geotechnical engineers.

\section{SUBSURFACE CONDITIONS}

Before the projects started, boreholes were driven to depths ranging from $31.0 \mathrm{~m}$ to $52.0 \mathrm{~m}$ to determine the subsurface. In total, 401 Standard penetration tests and dynamic penetration tests were conducted with the latter reaching the bottom of gravel and medium sand. In addition, based on the Chinese code CB50123-1999, laboratory tests were conducted to determine the soil characteristics of specific gravity, relative density, porosity, void ratio, saturation ratio, water content, plastic limit, liquid limit, plasticity index, liquidity index, direct shear test, cohesion and friction angle (consolidation shear test and triaxle tests (CU\& UU)) etc.

Through the interpretation of the borehole logs and parameters obtained from laboratory tests, the subsurface investigation found: 1) miscellaneous fill, which contains gravel, concrete and brick stone, construction waste and plant roots, with average depth of $2.5 \mathrm{~m}$; 2) yellowish-brown loess, plastic iron-manganese concretion, with average depth of $2.9 \mathrm{~m}$; 3) tawny silt, slight wet, low tenacity, with average depth of $2 \mathrm{~m}$; 4) silty clay, yellow and brown, medium to high plasticity, contains iron and manganese oxides, with average depth of $11.6 \mathrm{~m}$; 5) fine sand, brown, medium dense and wet, contains quartz arkose with average depth of $2.1 \mathrm{~m}$; 6) dark brown silty clay, contains iron and manganese oxides, with average depth of 10m; 7) silty clay, yellow, light brown, ironmanganese and calcareous concretion; this layer contained little sand, gravel with average depth of $8.3 \mathrm{~m}$; 8) coarse sand, brown, dense, saturated, with average depth of $3.6 \mathrm{~m}$; 9) clay, brown, high viscous with average depth of $2 \mathrm{~m}$. The soil parameters of these subsurface layers are summarized in Table 1.

Table 1 Soil parameters of subsurface layers

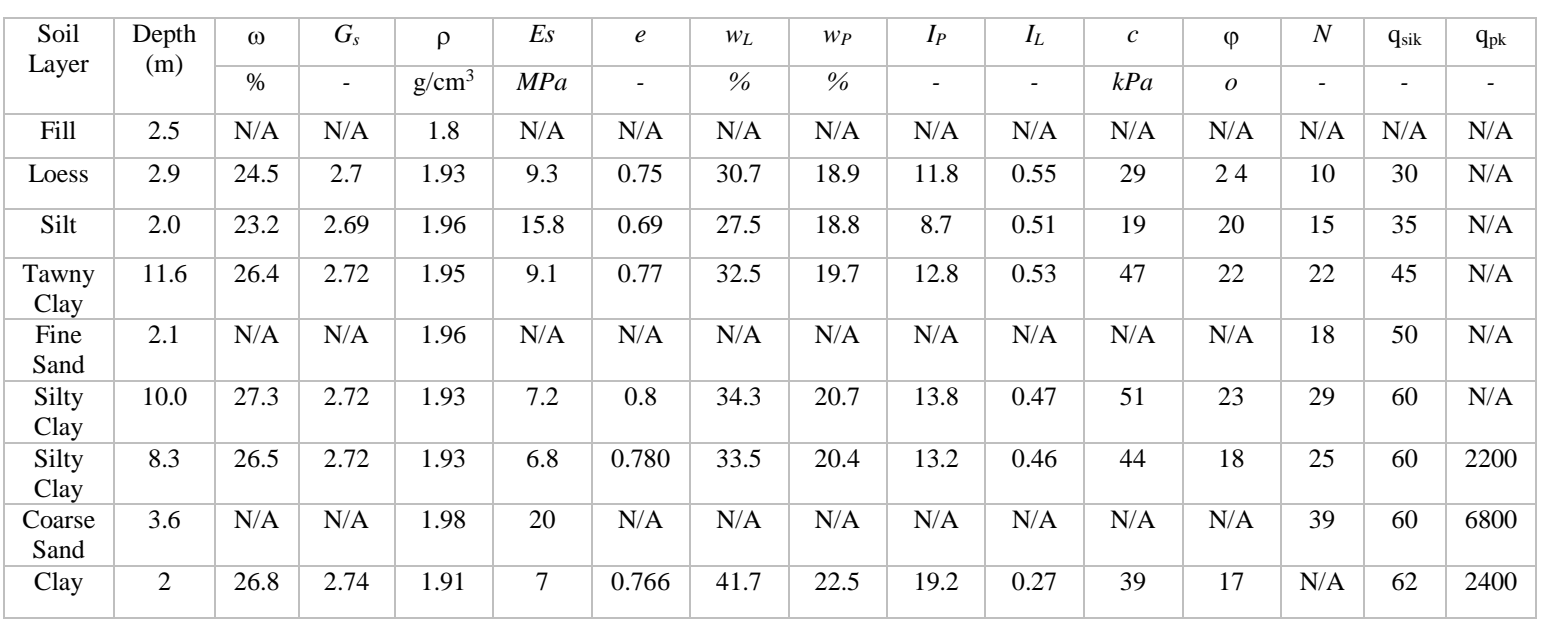




\section{PILE DESCRIPTIONS}

All six precast piles contained two parts with bolt connections as shown in Fig.1. The cross sections of these tested piles are all rectangular with side lengths of $700 \mathrm{~mm}$. The three lateral loaded piles and 3 uplift loaded piles are labeled as P15, P163, P152 and P138, P151, P165 respectively with the same concrete strength of C50 (characteristic strength of $50 \mathrm{Mpa}$, cubic test sample dimension of $150 \mathrm{~mm} \times 150 \mathrm{~mm} \times 300 \mathrm{~mm}$ ), and the same horizontal reinforcement of HRB400 (Hot-Rolled-Ribbed-Bar with yield strength of 400Mpa) and vertical reinforcement of HPB300 (Hot Rolled Plane Bar with yield strength of 300Mpa).

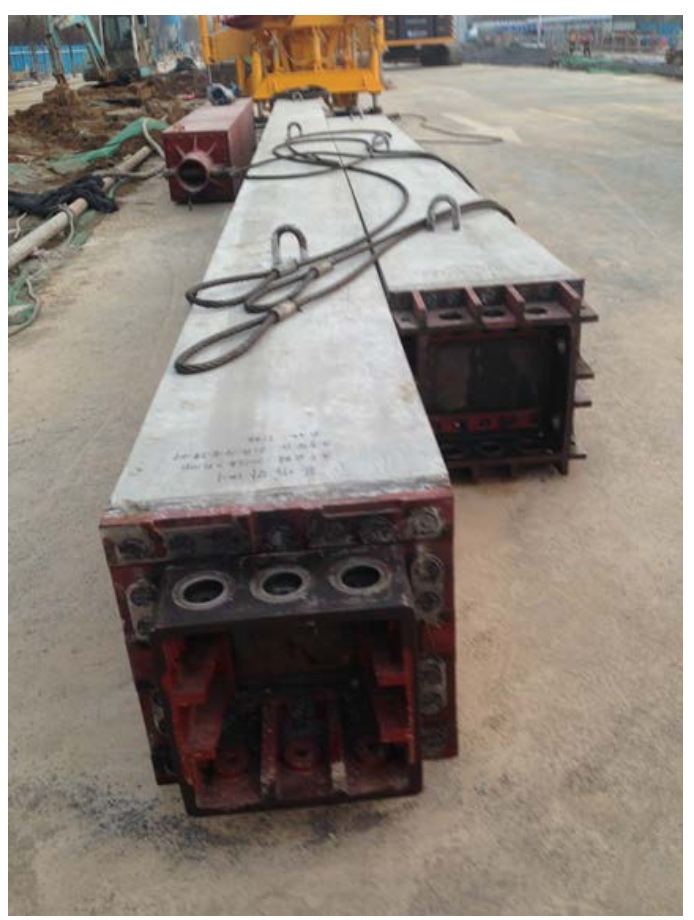

Fig. 1 Tested Non-displacement Precast Pile

The length of lateral loaded non-displacement piles P15, P163 and P152 were 24.7m, 26.6m and $28 \mathrm{~m}$, respectively. For the uplift loaded concrete piles of P138, P151, P165, the lengths were $24.7 \mathrm{~m}$, $26.6 \mathrm{~m}$ and $28 \mathrm{~m}$, respectively. Specifically, six pairs of strain gauges were installed in P165 for determining the uplift load transfer characteristics of this non-displacement precast pile.

The locations of each strain gauge, initial value, and $K$ value of strain gauges are summarized in Table 2. The stress of the strain gauge can be calculated by Eq. 1 using parameters from Table 2 and collected frequency data recorded on-site. The axial loading of the pile cross section then can be determined through Eq. 2.
Table 2 Strain Gauges Information

\begin{tabular}{|c|c|c|c|}
\hline $\begin{array}{c}\text { Depth } \\
(\mathrm{m})\end{array}$ & $\begin{array}{c}\text { Label of } \\
\text { Strain Gauge }\end{array}$ & $\begin{array}{c}\text { Initial } \\
\text { Value }\end{array}$ & $\begin{array}{c}K \\
\text { Value }\end{array}$ \\
\hline 2.3 & 285349 & 1442.9 & 0.00006695 \\
\hline 6.9 & 287918 & 1431.0 & 0.00006768 \\
\hline 11 & 28588 & 1410.5 & 0.00006423 \\
\hline 16 & 281245 & 1428.1 & 0.00007353 \\
\hline 21 & 286639 & 1415.2 & 0.00006673 \\
\hline 27 & 286556 & 1452.2 & 0.00006921 \\
\hline
\end{tabular}

$\overline{\sigma_{s}}=\frac{1}{n} \sum_{i=1}^{n}\left[K_{i}\left(f_{i n i}^{2}-f_{i}^{2}\right) / A_{s}\right]$

$N_{P}=\overline{\sigma_{s}}\left(\frac{E_{c}}{E_{s}} A_{c}+A_{s}\right)$

Where:

$N_{P}$ - is the force of concrete pile;

$\bar{\sigma}_{S}$ - is the average stress of vibration wire strain bar;

$E_{c}$ - is the Young's modulus of concrete;

$E_{s}$ - is the Young's modulus of steel;

$A_{c}$ - is the cross section area of concrete;

$A_{s}$ - is the cross section area of steel;

$K_{i}$ - is the coefficient of vibration wire stress rebar; $f_{i n i}$ - is the initial recorded frequency;

$f_{i}$ - is the recorded frequency of vibration wire stress rebar.

\section{INSTALLATION PROCESS OF PILES}

These piles were cast in factory which can control the contamination caused by cement dust and exhaust gas released during welding as shown in Fig. 2.

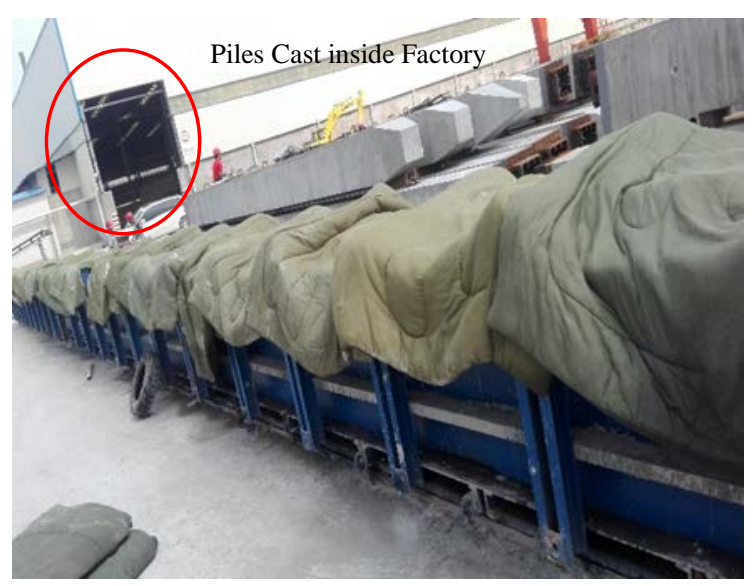

Fig. 2 Precast Piles in Factory

The construction process of installing these non-displacement precast concrete piles is:

1) Soil is removed from the required location by auger drilling machine as shown in Fig. 3; the drilled hole is $550 \mathrm{~mm}$ which is less than the side 
length of pile cross section so that there is no gap between pile and soil (Fig. 4).

2) After the first piece of the precast concrete pile is transferred to the required hole (Fig. 5), it is descended by a squeezing machine.

3) This squeezing machine clamps the first piece of the concrete pile so that it can be bolted to the second piece of pile as shown in Fig. 6.

Note that for P165, which was installed with stain gauges, the cables were separated and were cast in two pieces of the pile. The strain gauge cable which was separated in concrete pieces needed to be connected before bolting those pieces together. In order to avoid damaging this cable during the connection of the two concrete pieces, a small space was designed as shown in Fig. 1.

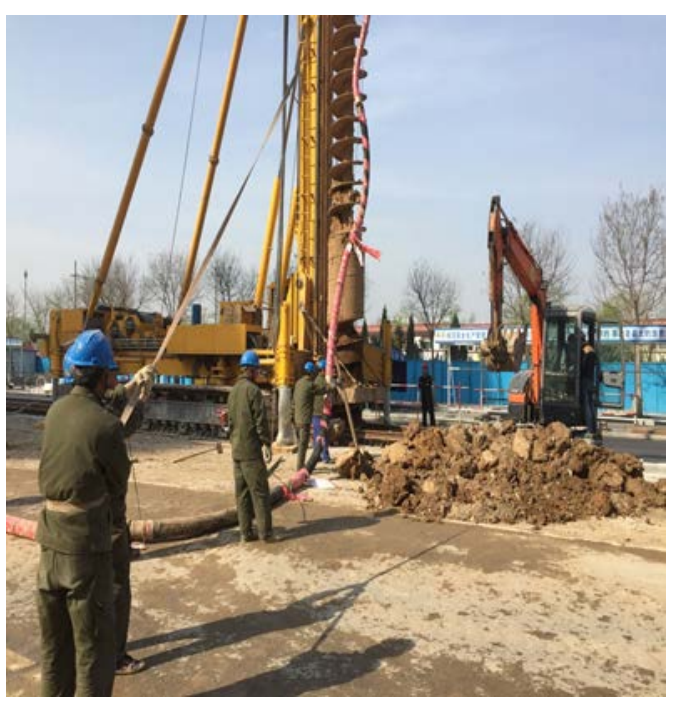

Fig. 3 Auger Drilling Machine

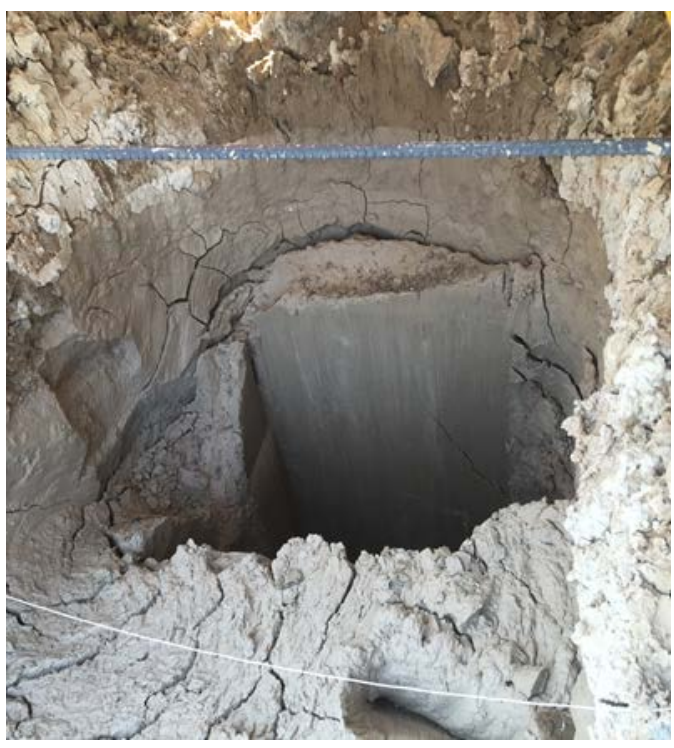

Fig. 4 Drilled hole for Precast Pile

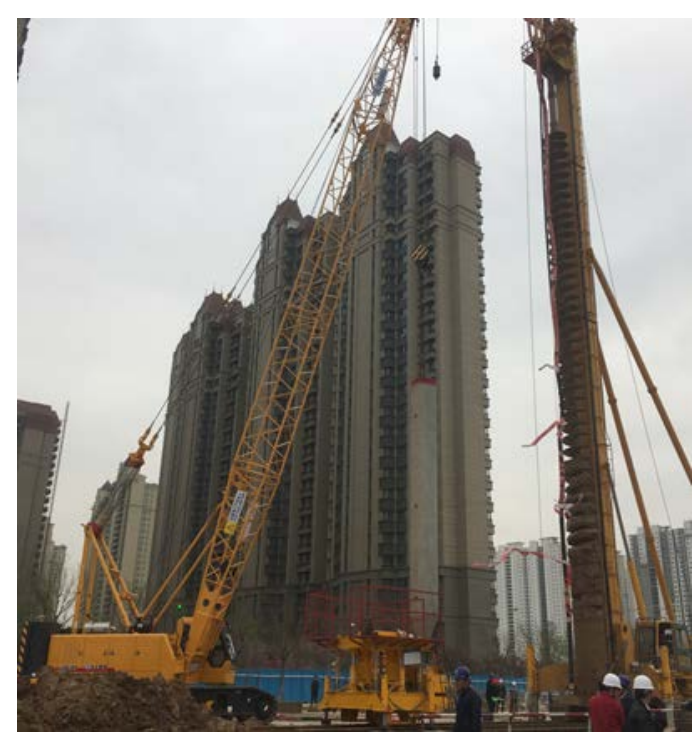

Fig. 5 Transferring Precast Piles

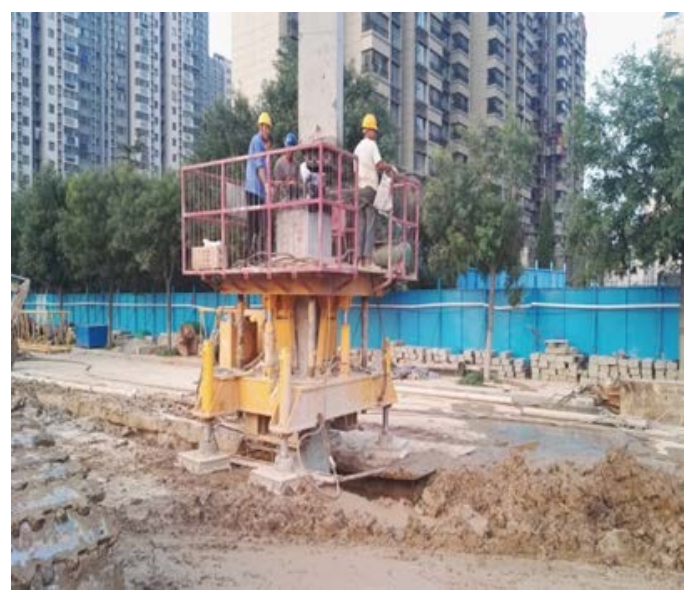

Fig. 6 After Lowering the First Piece of Pile

\section{TEST SET-UP}

As shown in Fig. 7 and Fig. 8, two reaction beams were used for lateral and uplift static load tests. One hydraulic cylinder and two hydraulic jacks were used for providing loads for lateral and uplift tests. Two dial gauges were located at the side of the pile to record horizontal movements of the head and four dial gauges were symmetrically installed on a reference bar to measure the vertical uplift movement of the pile head.

Horizontal cycling load tests were conducted based on Chinese codes JTJ 041-2000 [4] and JGJ94-2008 [5]. After the loading was applied, duration of four minutes was required before recording horizontal movement; additionally, after releasing loads back to $0 \mathrm{kN}$, duration of two minutes was required before recording residual displacement. During this test, five load circulations were required before the next loading was applied. The tests would have to stop if 1) the 
monitored horizontal movement of pile head exceeded 30mm or 2) concrete cracks emerged.

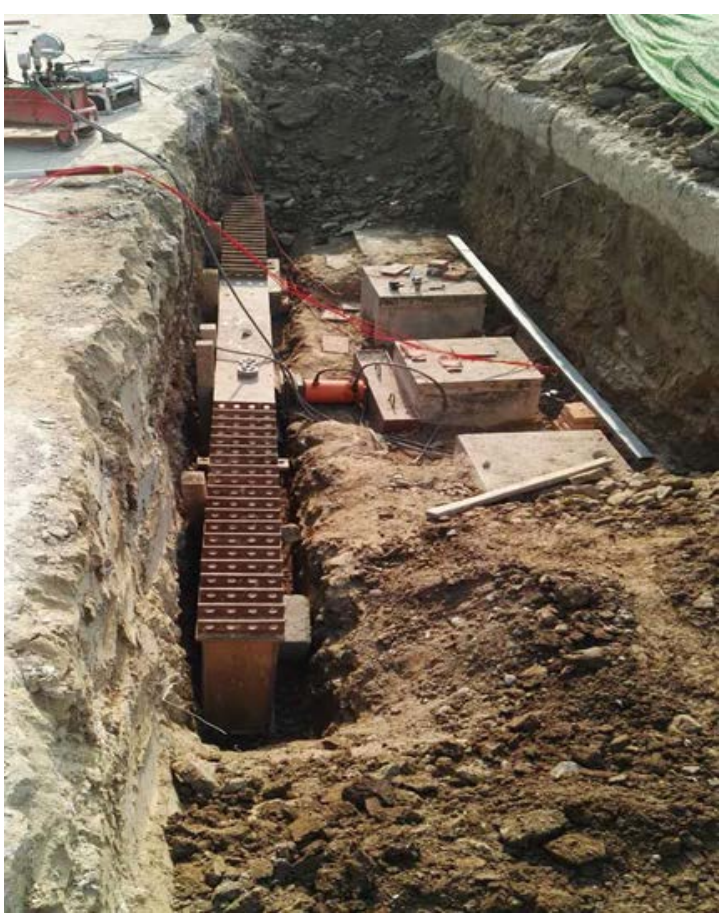

Fig. 7 Lateral Static Load Tests Set Up

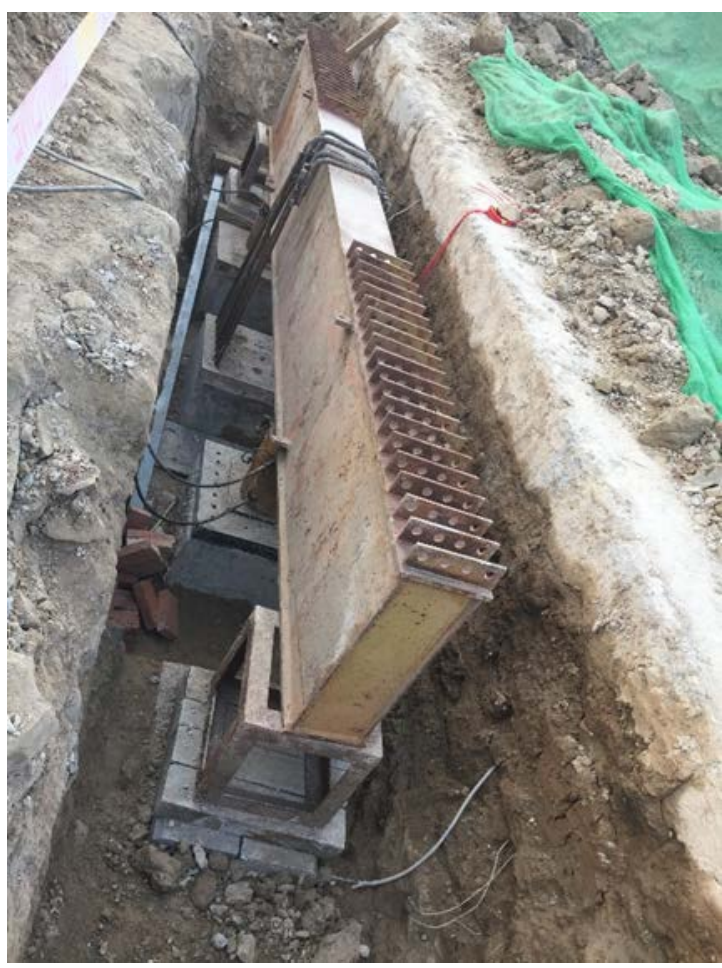

Fig. 8 Uplift Static Load Tests Set Up

For the uplift static load tests, low speed maintenance tests were conducted. The applied load was maintained until the rate of axial movement did not exceed to $0.1 \mathrm{~mm}$. After each load was applied, recording the vertical movement of piles with intervals of 5, 10, 15 minutes, and 30 minutes were required if accumulated time exceeded 1 hour. The loading could be terminated in the case of the following conditions: 1) the applied loading is equal to the value of 0.9 times the ultimate strength of reinforcement, or 2) quintuple movement change of previous loading is discovered or 3) pile head movement is increased up to $100 \mathrm{~mm}$.

\section{RESULTS AND DISCUSSION}

\subsection{Load-Settlement and Extrapolation of Horizontal SLTs}

The horizontal loads $\mathrm{H}$ and movement $\mathrm{X}$ of three tested precast piles were recorded as shown in Fig. 9-11. It can be seen that the critical load $\left(\mathrm{H}_{\mathrm{cr}}\right)$ of P15 is $100 \mathrm{kN}$. For the ultimate load, it seems to be $400 \mathrm{kN}$; however, there were some cracks observed after applying $300 \mathrm{kN}$, and thus the ultimate load is determined as $300 \mathrm{kN}$; for P163, the critical load was $200 \mathrm{kN}$, whilst the ultimate load $\left(\mathrm{H}_{\mathrm{u}}\right)$ was difficult to read and therefore interpretation is required; the $\mathrm{H}_{\mathrm{cr}}$ and $\mathrm{H}_{\mathrm{u}}$ of P152 are determined as $240 \mathrm{kN}$ and $480 \mathrm{kN}$, respectively.

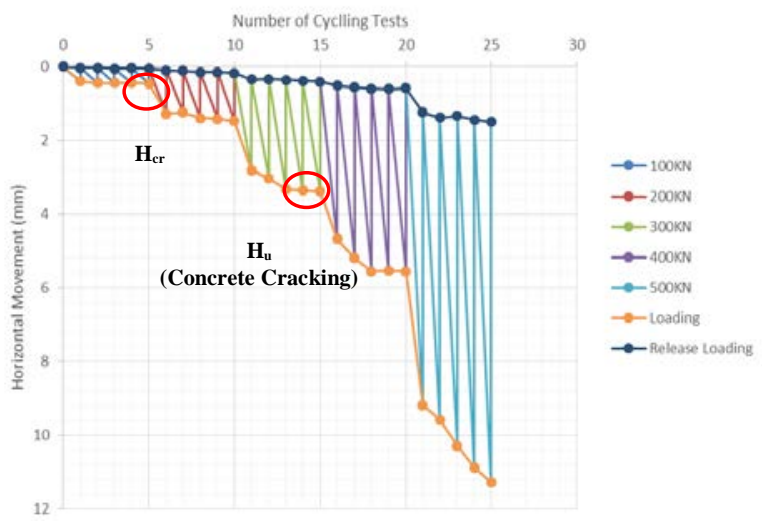

Fig. 9 H-X Curves of P15

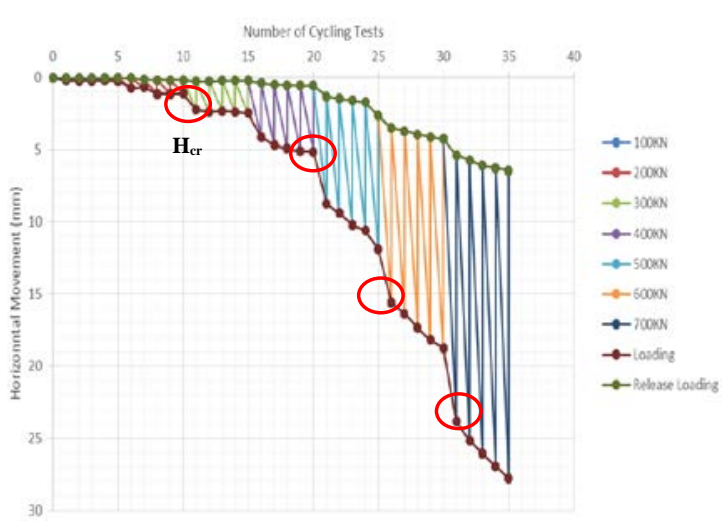

Fig. 10 H-X Curves of P163 


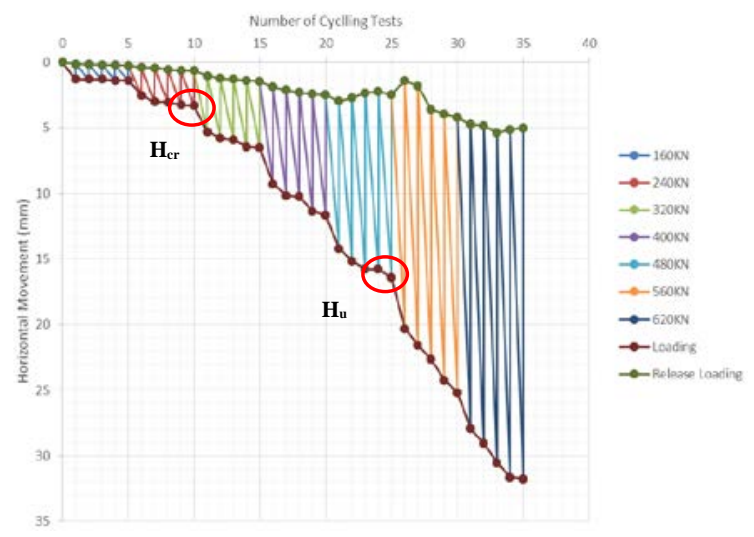

Fig. $11 \mathrm{H}-\mathrm{X}$ Curves of P152

The interpretation of the horizontal static load tests is provided in Fig. 12-14. Through establishing a coordinate system of horizontal loading versus nominated gradients settlement, three lines were discovered in each diagram. Two intersection coordinates demonstrates the corresponding $\mathrm{H}_{\mathrm{cr}}$ and $\mathrm{H}_{\mathrm{u}}$. The equations for each line are also illustrated in Fig. 12-14; the $\mathrm{H}_{\mathrm{cr}}$ and $\mathrm{H}_{\mathrm{u}}$ of P15, P163 and P152 are $107.5 \mathrm{kN}, 154.4 \mathrm{kN}$, $175.4 \mathrm{kN}$ and $280.9 \mathrm{kN}, 447.7 \mathrm{kN}, 470.8 \mathrm{kN}$ respectively.

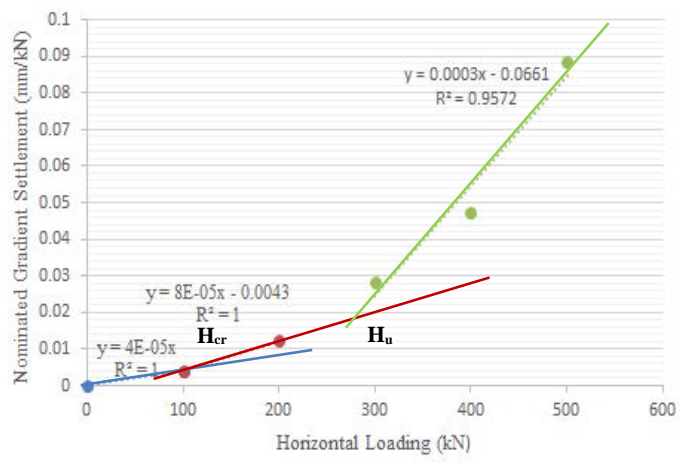

Fig. 12 Horizontal SLTs Interpretation of P15

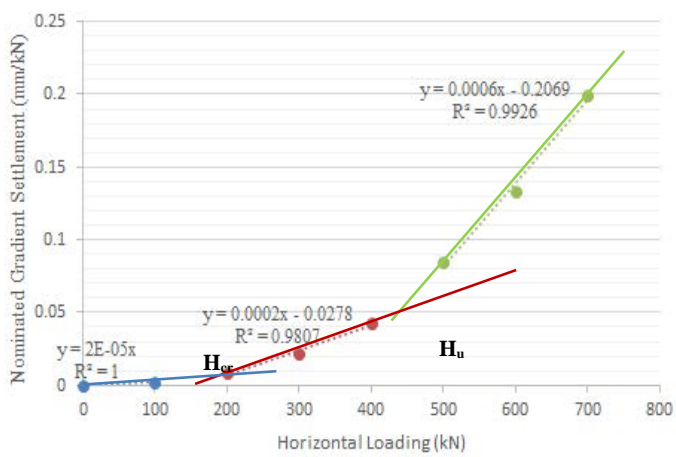

Fig. 13 Horizontal SLTs Interpretation of P163

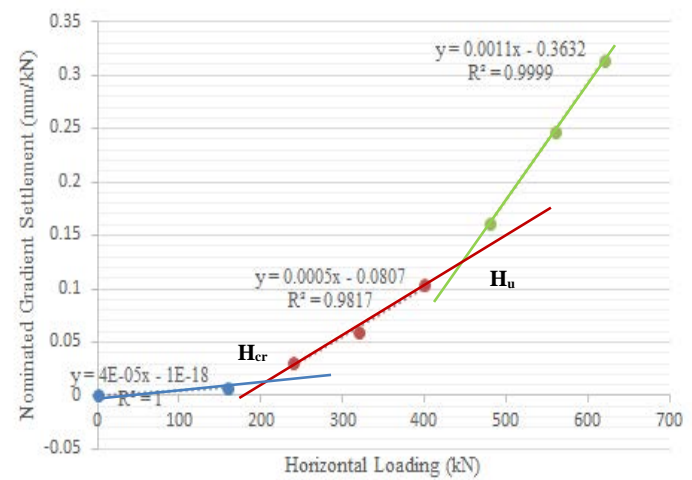

Fig. 14 Horizontal SLTs Interpretation of P152

The results of $\mathrm{H}-\mathrm{X}$ curves as well as interpretation of these static load tests are summarized in Table 3 . The results are close to each other and all demonstrate that the critical and ultimate loads of these non-placement precast piles increase with pile length. It is worth noting that sometimes it is difficult to determine the critical and ultimate load through $\mathrm{H}-\mathrm{X}$ curves, and therefore comprehensive analysis between static load tests and interpretation is required for geotechnical engineers.

Table 3 Static Load Test Results and Interpretation

\begin{tabular}{|c|c|c|c|c|c|}
\hline $\begin{array}{c}\text { Pile } \\
\text { Label }\end{array}$ & \multirow{2}{*}{$\begin{array}{c}\text { Pile } \\
\text { Length }\end{array}$} & \multicolumn{2}{|c|}{$\begin{array}{c}\text { Lateral Static Load } \\
\text { Tests Results }\end{array}$} & \multicolumn{2}{c|}{$\begin{array}{c}\text { Interpretation of } \\
\text { Static Load Tests }\end{array}$} \\
\cline { 3 - 6 } & & $\begin{array}{c}\text { Critic } \\
\text { Load }\end{array}$ & $\begin{array}{c}\text { Ultimate } \\
\text { Load }\end{array}$ & $\begin{array}{c}\text { Critic } \\
\text { Load }\end{array}$ & $\begin{array}{c}\text { Ultimate } \\
\text { Load }\end{array}$ \\
\cline { 2 - 6 } & $(\mathrm{m})$ & $(\mathrm{kN})$ & $(\mathrm{kN})$ & $(\mathrm{kN})$ & $(\mathrm{kN})$ \\
\hline P15 & 24.7 & 100 & 300 & 107.5 & 280.9 \\
\hline P163 & 26.6 & 200 & N/A & 154.4 & 447.75 \\
\hline P152 & 28.0 & 240 & 480 & 175.43 & 470.8 \\
\hline
\end{tabular}

\subsection{Load-Settlement Curves \& Extrapolation Uplift SLTs}

The load-movement curve results of the three uplift loaded piles are provided in Fig. 15. The maximum uplift movements of these pile heads were discovered as 1.73mm (P138), 1.6mm (P151) and $1.31 \mathrm{~mm}$ (P165) respectively when the maximum loading of $1900 \mathrm{kN}$ was applied. The corresponding residual uplift displacements of these three piles were $0.47 \mathrm{~mm}, 0.5 \mathrm{~mm}$ and $0.35 \mathrm{~mm}$, respectively.

As shown in Fig. 15, all three lines are approximately linear, so the maximum loadings of $1900 \mathrm{kN}$ are not the ultimate bearing capacity of these three piles. Interpretation of this diagram then is needed.

The ultimate uplift bearing capacity of nonfailure uplift SLTs can be determined by Modified Mazurkiewicz method [6] The assumption is that the Nominate Settlement (Load/Settlement) value is equal to 0 when the loading is small and the 
settlement is very high; the dashed line would be go through by y-axis which illustrates the uplift ultimate bearing capacity of the pile. In Fig. 16, the equations representing these three lines are provided in Eq. 3-5. The ultimate bearing uplift bearing capacities of P138, P151 and P165 are $2903.6 \mathrm{kN}, 3467.0 \mathrm{kN}$ and $4724.2 \mathrm{kN}$, respectively. As summarized in Table 4, the uplift bearing capacity of these non-displacement piles increases with the pile length.

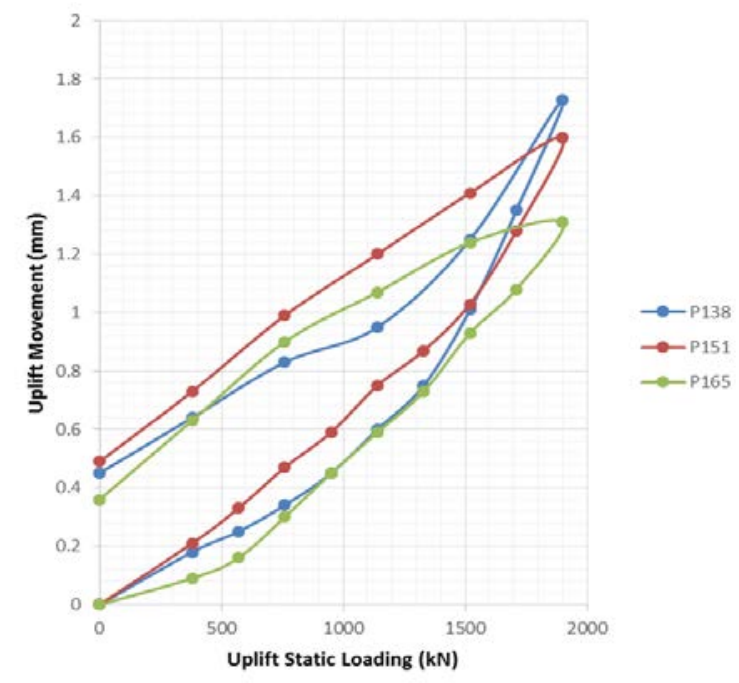

Fig. 15 Uplift Static Load Tests

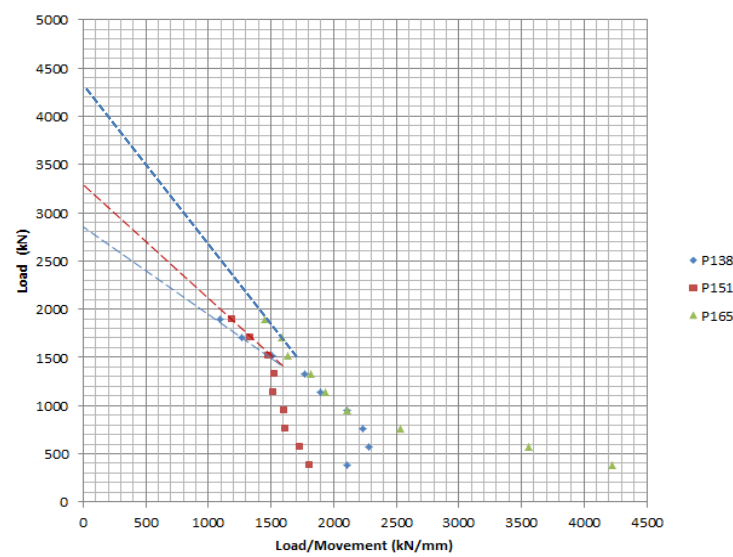

Fig. 16 Modified Mazurkiewicz Method

P138: $y=-0.9253 x+2903.6$

$\mathrm{P} 151: \mathrm{y}=-1.318 \mathrm{x}+3467$

$P 165: y=-1.371 x+4724.2$

Table 4 Static Load Test Results and Interpretation

\begin{tabular}{|c|c|c|c|}
\hline Pile & \multirow{2}{*}{$\begin{array}{c}\text { Pile } \\
\text { Label }\end{array}$} & $\begin{array}{c}\text { Uplift Static Load } \\
\text { Tests Results }\end{array}$ & $\begin{array}{c}\text { Interpretation of } \\
\text { Static Load Tests }\end{array}$ \\
\cline { 3 - 4 } & & $\begin{array}{c}\text { Ultimate Load } \\
(\mathrm{kN})\end{array}$ & $\begin{array}{c}\text { Ultimate Load } \\
(\mathrm{kN})\end{array}$ \\
\hline P138 & 24.7 & N/A & 2903.6 \\
\hline P151 & 26.6 & N/A & 3467.0 \\
\hline P165 & 28.0 & N/A & 4724.2 \\
\hline
\end{tabular}

\subsection{Load Transfer Characteristics of Uplift SLTs}

The vibration frequency obtained from strain gauges in P165 was recorded at each loading stage. Through Eq. 1-2, the average axial uplift loads were determined along the pile. As shown in Fig. 17 , the axial force decreases with depth along the pile and increases with applied loads provided by hydraulic jacks $[7,8]$. This is caused by friction resistance provided by soil layers. The accumulated friction resistance along the pile is shown in Fig. 18.

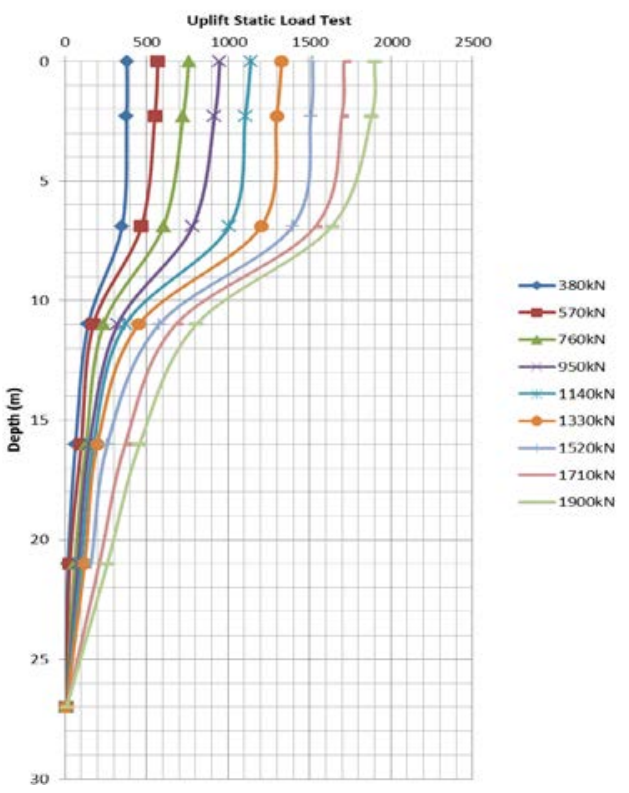

Fig. 17 Load Transfer in Pile

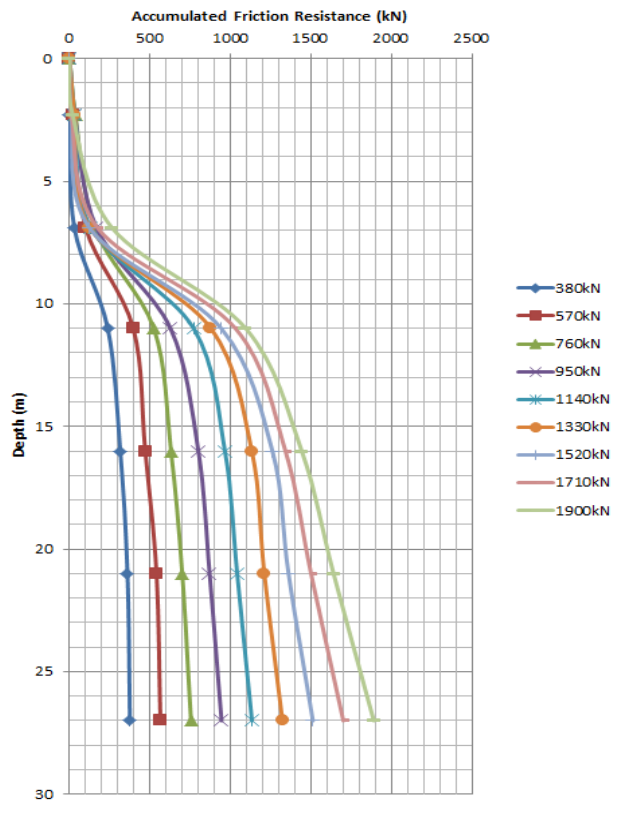

Fig. 18 Accumulated Shaft Resistances 


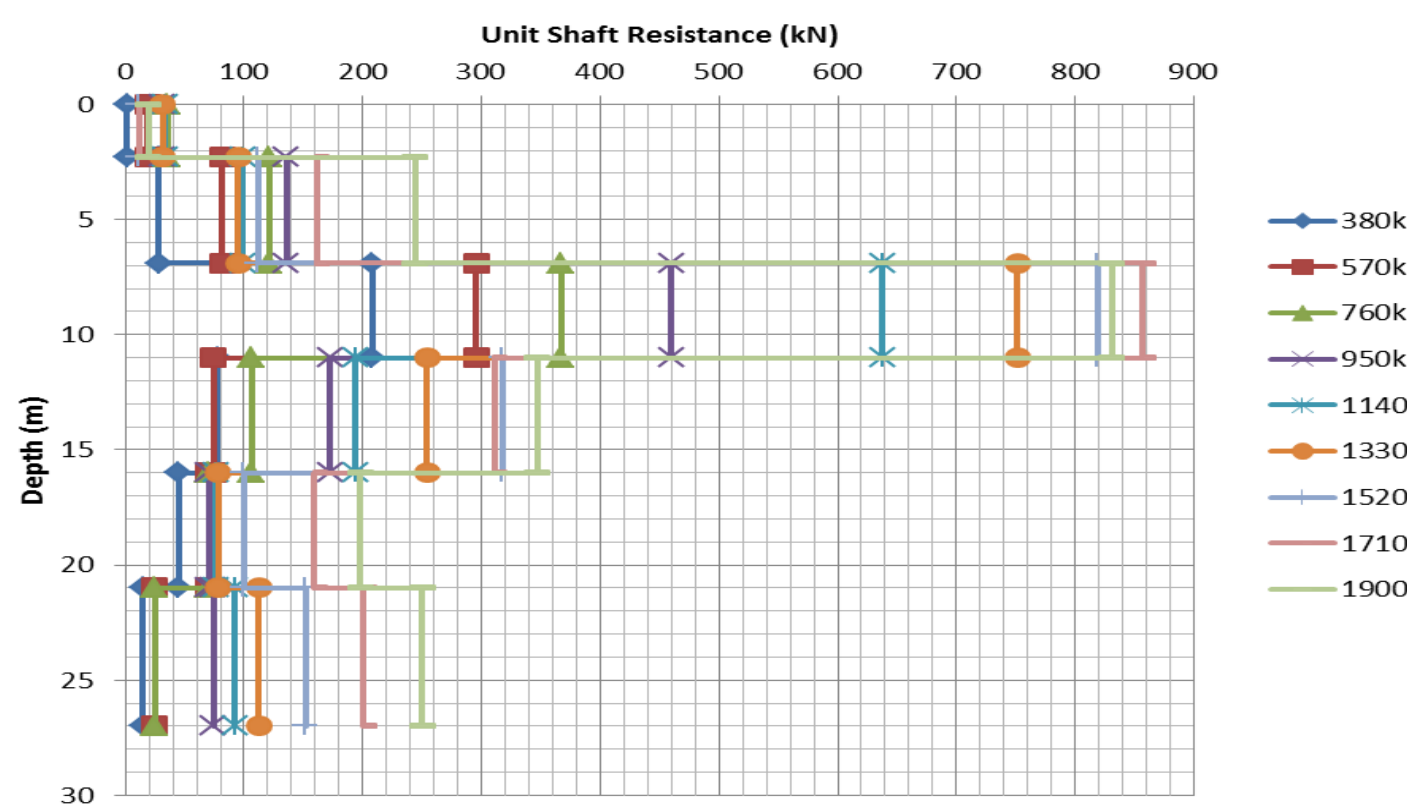

Fig. 19 Unit Shaft Resistance of P156

The distribution of unit shaft resistance is obtained by calculating differences between two adjacent axial loads acquired from the strain gauges. As shown in Fig. 19, when the uplift lift loading increases, the friction loading of each soil layer increases. It also shows that the soil layer from $7 \mathrm{~m}-16 \mathrm{~m}$ plays the most significant role in resisting the uplift force. Furthermore, this indicates that before the loading stage of $1330 \mathrm{kN}$ was applied, the friction resistance of soil layer from $7 \mathrm{~m}-11 \mathrm{~m}$ showed a rapid increasing trend, and after this stage, the friction resistance of the soil layer from $21 \mathrm{~m}-27 \mathrm{~m}$ showed a rapid growth.

\section{CONCLUSIONS}

This paper illustrates the construction process of non-displacement precast piles used to avoid a soil compaction effect and to diminish associated environmental problems. Three lateral and three uplift static load tests were conducted and the results were provided for capacity analysis. The test methods as well as interpretation of these tests are also illustrated in this paper. It is concluded that the critical and ultimate load of lateral loaded precast piles and ultimate load of uplift loaded piles increases with increased pile length.

The unit shaft resistances and propagations of friction resistances were analyzed to investigate the load transfer behavior of these nondisplacement precast piles. This data is valuable for designing and theoretical investigation and therefore this paper can provide practical information for geotechnical engineers.

\section{REFERENCES}

[1] Ma, S. C., Li G. Z. The Relationship between Economic Increase of China and Environmental contamination Based on Kuznets Curves Analysis, 2006. Statistical Research, No. 8, pp. 37-40.

[2] Environtology. China's top ten environmental problems 2011, viewed 21 February 2017. < http://baike.baidu.com/item/\%E4>.

[3] Environtology. China's construction waste recycling suffered from serious environmental pollution growing pains 2011, viewed 21 February 2017, < http://www.chinanews.com /gn/2011/1014/3389008.shtml>.

[4] Chu, E. H. Base Grouted Bored Pile on Weak Granite (2004). Grouting and Ground Treatment, ASCE 2004.

[5] JTJ041-2000, (2000). Technical Specifications for Construction of Highway Bridges and Culverts.

[6] JGJ94-2008. (2008). Technical Code for Testing of Building Foundation Piles pp.19-24

[7] Weeraya, C., \& Narin, M. (2013). Estimation of Uplift Pile Capacity in the Sand Layers. Int. Transaction Journal of Engineering pp. 57-65.

[8] Hossain, M.Z. and Awal, A.S.M.A., Experimental validation of a theoretical model for flexural modulus of elasticity of thin cement composite, Construction and Building Materials, Vol. 25, No. 3, pp.1460-1465, 2011.

Copyright (c) Int. J. of GEOMATE. All rights reserved, including the making of copies unless permission is obtained from the copyright proprietors. 